Best Practices/Essays

JSARD

ISSN: 2470-850X Online

Vol. 4, Issue 1 (2019), pp. 18-23

ISARD.org

\title{
Systems Thinking for Principals of Learning- Focused Schools
}

\author{
Haim Shaked, Hemdat Hadarom College of Education, Israel \\ Chen Schechter, Bar-Ilan University, Israel
}

\begin{abstract}
Systems thinking involves attempts to understand and improve complex systems, examines systems holistically, and focuses on the way that a system's constituent parts interrelate. This essay provides examples of how systems thinking can enable principals to demonstrate instructional leadership and nurture learning-focused schools in the current era of complexity, diversity, and accountability. These examples illustrate how systems thinking contributes to developing school curriculum, empowering professional learning communities, and fostering performance data interpretation. Overall, systems thinking offers a comprehensive way of both conceptualizing and practicing leadership for learning within the entire school setting, which leads directly to enhancing the quality of instruction and raising students' achievement.
\end{abstract}

Keywords: systems thinking, school principals, leadership for learning, curriculum, professional learning communities, data interpretation

The contemporary expectations for outcome-based accountability hold the staff in each school as directly accountable for improving its students' academic progress and outcomes. Understandably, as the chief figure at the helm, the school principal is thus held personally accountable for bringing about measurable student achievement and for demonstrating bottomline results. To this end, the principal needs to become a learning-focused instructional leader who ensures that every student receives the highest quality instruction each day and is, therefore, intensely engaged in the improvement of curriculum and instruction (Stronge, 2018). Within this reality, the traditional tools at the disposal of principals' are simply not enough. To guide them toward success, they sorely need comprehensive frameworks that are accompanied by complementary practical strategies.
Systems thinking, which has been proposed as an approach for management in richly interconnected problem situations (Jolly, 2015; Wilson \& Van Haperen, 2015), may offer a valuable theoretical and practical answer to this noticeable and urgent contemporary need in schools (Fullan, 2014; Senge et al., 2012). Insofar as research has demonstrated that systems thinking helps in dealing with various domains of educational leadership (e.g., Crick, Barr, Green, \& Pedder, 2017; Finnigan \& Daly, 2016; Kensler, Reames, Murray, \& Patrick, 2011), this article will discuss some possible contributions of systems thinking to the learning-focused work of school principals within complex and changing environments.

\section{Defining Systems Thinking}

Systems thinking is an approach that puts the study of wholes before that of parts (Senge, 2006). That is, this approach does not try to break systems down into parts in order to understand them; instead, it concentrates on how the parts act together in networks of interactions (Gharajedaghi, 2011). Put differently, systems thinking provides a means of seeing the system as an integrated, complex composition of many interconnected components that need to work together in order for the whole to function successfully (Arnold \& Wade, 2015). Despite the absence of a common well-accepted definition for systems thinking, it is quite clear that this construct has two main complementary meanings: On the one hand, seeing the whole beyond the parts refers to rising above the separate components to see the whole system. On the other hand, seeing the parts in the context of the whole refers to thinking about each separate component as a part of that whole system, while emphasizing the components' interrelationships rather than the components themselves (Shaked \& Schechter, 2014). Hence, altogether, systems thinking 
involves a holistic point of view, which is oriented toward seeing the "big picture" and not only its separate parts. It also incorporates multiple perspectives of the system, while considering the interconnections and mutual influences among its elements and parts (Boardman \& Sauser, 2008).

As systems thinking enables management over situations characterized by dynamic change, diversity, and complexity, it is considered a beneficial management approach (Brown, 2012; Jolly, 2015; Wilson \& Van Haperen, 2015). Particularly, the potential contribution of systems thinking to various educational issues has been highlighted by several researchers (e.g., Dyehouse et al., 2009; Kensler et al., 2011). In recent years, the authors have been investigating some important applications of systems thinking in school settings (e.g., Shaked \& Schechter, 2013, 2014, 2016a, 2017, 2018). Our research was conducted within the Israeli educational system, which demands school principals to serve as instructional leaders in order to improve the education and learning of all students. According to the Gini coefficient for measuring a nation's distributive inequality, Israel is among the western countries with the broadest gap between rich and poor, alongside the United States and the United Kingdom, experiencing great diversity among school populations and a wide gap in students' achievement distributions (Organisation for Economic Cooperation and Development, 2016). As seen in the following descriptions, systems thinking can serve school principals in many areas, including the development of school curricula, the facilitation of effective professional learning communities, and the interpretation of performance data, which are all essential for nurturing a learning-focused school in contemporary outcome-based accountability environment.

\section{Developing School Curriculum}

As instructional leaders, school principals are also expected to serve as curriculum leaders (Glickman, Gordon, \& Ross-Gordon, 2017). Systems thinking can enable the design and implementation of school curricula from a holistic perspective. Emphasizing the importance of the whole and the interdependence of its parts, systems thinking assists in grasping the big picture--both in terms of the curriculum's numerous components and in terms of how that particular curriculum may interrelate with myriad other school practices and subjects. From the systems thinking perspective, systemic coordination of curriculum with various disciplinary contents, instruction and assessment practices, and policy issues is vital to raise student achievement levels. This is because such coordination results in clear and consistent expectations for teaching and learning, addressing the changing needs of students and teachers. This coordination of school curricula reflects seeing the whole beyond the parts, which is one of the meanings of systems thinking. Namely, beyond improving each of these areas separately, the systems thinking approach upholds that these areas should fit in well with each other. Moreover, considering that the ultimate goal of accountable schools is to improve their students' achievement levels, which are measured by standards -based assessments, all of these aspects--the curriculum, the instruction, and the assessments-need to be aligned with standards for the particular age group and population at hand. From the systemsthinking perspective, improving each component separately will not result in improvement of the whole, because the whole goes beyond the mere sum of its parts.

Such coordination of standards, curriculum, instruction, and evaluation is not a topic necessitating one-time treatment in schools; rather, it is an ongoing, dynamic process. Moreover, it is not a task for school leaders exclusively. This is an issue to be dealt with by all teachers. This can be illustrated by the following remark of one of the dozens of Israeli principals interviewed for our series of studies on this topic:

I established staff meetings during which teachers work together to interpret the standards, study the curriculum, share effective teaching strategies, examine benchmarks, and analyze student work. I want the teachers to see the connections between all the links of the chain, because they are all dependent on each other.

The systems thinking approach can also strengthen the ties between the various horizontal disciplines that all may interconnect as relevant to a particular curriculum at a specific grade level. As just one example, developing students' reading skills is a goal to be achieved not only in language lessons, but during all other lessons as well, such as history or science. Moreover, unless the strategies that teachers impart in reading lessons are applied and practiced regularly by students during all classes, reading skills may only be partially absorbed, thereby limiting students' reading acquisition.

Similarly, the systems thinking perspective also facilitates holistic development of curriculum vertically, among different age levels. Designing curricula at the systems level enables the different school units to be seen as parts of one continual process, as explained by a principal: 
The syllabus for all age levels is cyclic, meaning that we always review the previous material when we are about to teach a new subject. The problem is that in our school there's a break between every two levels. But you are not only the teacher of your own pupils; you are a team member. Teachers should know a bit more than just what happens in their own classroom, because the curriculum of all age levels is actually a continuous one.

Knowing more than just what is happening in one's own classroom reflects seeing the whole beyond the parts because each grade-level's curriculum does not stand alone to be learned only once within a short period of time. Instead, the curriculum spirals up, with materials being revisited repeatedly over the years at more complex and abstract levels in accordance with students' growing abilities.

\section{Empowering Professional Learning Communities}

Systems thinking offers vast potential for enabling the development of school-based professional learning communities, where educators collaborate to improve teaching skills and students' academic performance. In such a professional learning community, the school staff members meet to openly discuss central questions such as: What do we expect our students to learn? Which of our school's features and practices have been most successful in helping students attain high levels of achievement? How could we adopt these characteristics and practices in our other classrooms? What commitments would we have to make to one another to create a higher achieving school? Which indicators could we monitor to assess our progress? By compiling shared knowledge and locating common ground regarding such questions, the school can build a solid foundation upon which to move forward with its improvement initiatives (Salo, Nylund, \& Stjernstrøm, 2015).

Systems thinking provides a sound conceptual basis for forming a professional learning community at school, because through the lens of systems thinking teachers become active members of one large organization that operates as an integrated whole working to improve the entire school together, as asserted by a principal:

I believe that a school teacher is not only the teacher of her own students; she is a part of the school team, which is responsible for all students' learning. For this reason, I expect every professional in the school to engage with colleagues in an ongoing exploration of crucial questions that drive our work, because if you like it or not--you are part of a joint development process of the whole school. Systemically, a single teacher should focus not only on his or her position, but rather should feel responsible for the whole school's output, and therefore engage in collaborative learning. This point of view, which considers each teacher as a part of a whole team, reflects seeing the parts in the context of the whole, which is one of the two main aspects of systems thinking.

Not only does systems thinking provide the conceptual justification for the foundation of professional learning communities, but it also redefines the meaning of being a school leader. From the systems thinking standpoint, leaders should enable collaborative work to establish common goals. Another principal articulated this notion:

In my opinion, principals should not impose their own predetermined way. They must respect various voices and work to find a common path. They should lead from the center rather than from the top and concentrate on presenting core questions. I believe that joint discussion of these questions will result in better school performance. By concentrating on the presentation of core systemic questions and the opening up of joint discussion of these questions, leaders can successfully bring about leadership that emanates from members of teams, and not simply from the appointed leader, thereby resulting in better school performance. In other words, a school leader does not have to be the smartest person in the room; the kind of wisdom that leaders need is a systemic wisdom, facilitating dialogue and collaboration among the teaching staff.

\section{Fostering Interpretation of Performance Data}

As schools face increasing pressure to improve student achievement, the use of data has become especially important. Armed with data and the means to harness the information it can provide, instructional leaders can bring about changes that more effectively target improvement in student achievement (Murphy, Neumerski, Goldring, Grissom, \& Porter, 2016). For example, data may spur decisions to refine instructional methods in light of identified problem areas or to dedicate additional individual instruction time to students who are struggling with particular subjects. Systems thinking facilitates such data analysis and evidence-based decision making.

The interpretation of data according to systems thinking involves adopting a multidimensional view. Each and every element or part within the large and complex school system inevitably has a context that influences it. Therefore, there is always more than one reason, explanation, implication, or answer related to that part or element of interest. Thus, principals can 
genuinely come to understand what data mean within the complex system only once they learn to consider any single occurrence at school as having several causes. It is this systemic perspective that can enable principals to view a single explanation for a phenomenon as unsatisfactory because there is never any single reason that can adequately and fully explain anything that happens in a school, or anywhere, for that matter. To illustrate, a principal did not agree with her team members who pointed to a supposedly "sole and exclusive" explanation:

There's always somebody, or a few somebodies, who know the exact cause for the problem at hand. I believe there's never one single reason for anything that happens in a school, or anywhere, for that matter. A school is such a complicated entity, consisting of so many components that influence each other, that there are always quite a few reasons for anything that occurs in it. In the modern-day school, so many components influence each other that there will always be multiple reasons that can aptly explain any phenomenon that occurs within it. Of course, some of these reasons will be primary and some will be secondary. However, decision making may improve if school leaders, in their role as data analysts, refrain from looking for and pinpointing a single underlying reason for a piece of data and instead become habitual seekers of the varied factors that might be involved in the system as a whole.

When schools invest efforts in improving student achievement, they obviously expect to improve future results. From the systems thinking perspective, it is important to understand that taking action toward the improvement of student achievement often does not yield immediate results. Problems may arise when school teams are not aware of the impact of this delay on the process of improving achievement, in which case they may misread early follow-up data and give up on the pursued course of action entirely. Thus, any interpretation of data should take into account that improvement efforts require a considerable investment of resources, time, and purposeful attention. A principal whose school was in the midst of a large-scale change with seemingly disappointing results explained,

We need to carefully examine what we are not doing right. Our improvement efforts require a considerable investment of resources, time, and purposeful attention, and the results are indeed disappointing. However, I believe they may be noticeable only after a while. We have to make decisions with discretion, and not shelve our improvement plan too early.
School leaders should carefully adjust their decisions to consider the possibility of delayed feedback and should prepare for time lags between actions taken and the appearance of expected results. Overreactions, too early, could cause the system to regress.

\section{Conclusion}

Altogether, the examples and possible directions described here for systems thinking implementation in school settings demonstrate potential uses of a systems-thinking approach to maximize teaching improvement and ensuring high quality learning opportunities for all students. Particularly, systems thinking pertains to some facets of instructional leadership. As instructional leaders, school principals are expected to serve as curriculum leaders (Glickman et al., 2017). Another aspect of instructional leadership is developing a school-based professional learning community, which can facilitate teachers' ongoing work processes by assisting them in reaching agreement upon the best teaching practices possible through reflective dialogue and action research (Salo et al., 2015). Effective use of data is also an aspect of instructional leadership (Murphy et al., 2016). Systems thinking may help principals enact these aspects of instructional leadership. However, not all aspects of instructional leadership benefit from systems thinking. For example, our previous research did not point to systems thinking as enabling supervision of instruction or protection of instructional time (Shaked \& Schechter, 2016b).

Many other applications of systems thinking could be implemented to enhance student learning and academic results. In this context, systems thinking is not a tool for school leaders but rather a school leadership approach, in which the term "approach" refers to a comprehensive way of both conceptualizing and practicing within the entire work setting. Systems thinking may be seen as a perspective about school leadership, which offers a way to consider events, people, and processes.

Nurturing principals' systemic thinking and actions with regard to the array of elements that interact within the complex, changing school environment --including curriculum, instruction, assessment, data interpretation, staff teamwork, and policy--may increase their ability to meet the very high expectations posed by today's era of accountability. Therefore, principals are encouraged to develop their systems-thinking perspective, which may assist them in fulfilling their instructional leadership role. It seems advisable to discuss systems thinking concepts and applications with prospective and current principals, in various stages of their 
educational careers, such as in preparation programs, mentoring programs provided to beginning principals, and other principal professional development.

Systems thinking may be useful not only for the principal but also for the entire school as an organization. It would therefore be advisable for future researchers to explore how principals' systems thinking characteristics influence other leaders within the school. In addition, further research may explore how systems thinking allows for the integration of instructional and transformational leadership, which differ from each other. Instructional leadership is primarily concerned with directing principals' influence due to its focus on improving teaching and learning. The processes by which improvement occurs are secondary to this orientation. In contrast, transformational leadership deals mainly with the ways in which leaders exert their influence on their followers. Leaders are thought to inspire their colleagues and to raise their followers' commitment to organizational goals. Systems thinking should be explored as an approach enabling the combination of these two approaches.

\section{References}

Arnold, R. D., \& Wade, J. P. (2015). A definition of systems thinking: A systems approach. Procedia Computer Science, 44, 669-678.

Boardman, J. T., \& Sauser, B. J. (2008). Systems thinking: Coping with $21^{\text {st }}$ century problems. Boca Raton, FL: CRC.

Brown, J. (2012). Systems thinking strategy: The new way to understand your business and drive performance. Bloomington, IN: iUniverse.

Crick, R. D., Barr, S., Green, H., \& Pedder, D. (2017). Evaluating the wider outcomes of schools: Complex systems modelling for leadership decisioning. Educational Management Administration \& Leadership, 45(4), 719-743.

Dyehouse, M., Bennett, D., Harbor, J., Childress, A., \& Dark, M. (2009). A comparison of linear and systems thinking approaches for program evaluation, illustrated using the Indiana interdisciplinary GK-12. Evaluation and Program Planning, 32(3), 187-196.

Finnigan, K. S., \& Daly, A. J. (2016). Why we need to think systemically in educational policy and reform. In: A. J. Daly \& K. S. Finnigan (Eds.), Thinking and acting systemically: Improving school districts under pressure (pp. 1-9). Washington, DC: American Educational Research Association.

Fullan, M. (2014). The principal: Three keys to maximizing impact. San Francisco, CA: Jossey-Bass.
Gharajedaghi, J. (2011). Systems thinking, managing chaos and complexity: A platform for designing business architecture ( $3^{\text {rd }}$ ed.). Burlington, MA: Morgan Kaufmann.

Glickman, C. D., Gordon, S. P., \& Ross-Gordon, J. M. (2017). Supervision and instructional leadership: A developmental approach (10th ed.). London, UK: Pearson.

Jolly, R. (2015). Systems thinking for business: Capitalize on structures hidden in plain sight. Portland, OR: Systems Solutions.

Kensler, L. A. W., Reames, E., Murray, J., \& Patrick, L. (2011). Systems thinking tools for improving evidence-based practice: A cross-case analysis of two high school leadership teams. High School Journal, 95(2), 32-53.

Murphy, J., Neumerski, C. M., Goldring, E., Grissom, J., \& Porter, A. (2016). Bottling fog? The quest for instructional management. Cambridge Journal of Education, 46(4), 455-471.

Organisation for Economic Co-operation and Development [OECD]. (2016). Education at a glance 2016: OECD indicators. Paris: Author. Retrieved from $h t t p: / / w w w . o e c d . o r g / e d u / e d u c a t i o n-a t-a-g l a n c e-$ 19991487.htm

Salo, P., Nylund, J., \& Stjernstrøm, E. (2015). On the practice architectures of instructional leadership. Educational Management Administration $\mathcal{E}$ Leadership, 43(4), 490-506.

Senge, P. (2006). The fifth discipline: The art and practice of the learning (2rd ed.). New York, NY: Currency, Doubleday.

Senge, P., Cambron-McCabe, N., Lucas, T., Smith, B., Dutton, J., \& Kleiner, A. (2012). Schools that learn: A fifth discipline fieldbook for educators, parents and everyone who cares about education. New York, NY: Crown.

Shaked, H., \& Schechter, C. (2013). Seeing wholes: The concept of systems thinking and its implementation in school leadership. International Review of Education, 59(6), 771-791.

Shaked, H., \& Schechter, C. (2014). Systems School Leadership: Exploring an emerging construct. Journal of Educational Administration, 52(6), 792-811.

Shaked, H., \& Schechter, C. (2016a). Sources of systems thinking in school leadership. Journal of School Leadership, 26(3), 468-494.

Shaked, H., \& Schechter, C. (2016b). Holistic school leadership: Systems thinking as an instructional leadership enabler. NASSP Bulletin, 100(4), 177202.

Shaked, H., \& Schechter, C. (2017). Systems thinking for school leaders: Holistic leadership for excellence in education. Cham, Switzerland: Springer. 
Shaked, H., \& Schechter, C. (2018). Holistic school leadership: Development of systems thinking in school leaders. Teachers College Record, 20(2), 1-40.

Stronge, J. H. (2018). Qualities of effective principals (3rd ed.). Alexandria, VA: Association for Supervision and Curriculum Development.

Wilson, B., \& Van Haperen, K. (2015). Soft systems thinking, methodology and the management of change. London, UK: Palgrave.

\section{Authors}

Haim Shaked, PhD, is Vice President for Academic Affairs at Hemdat Hadarom College of Education, Netivot, Israel. As a scholar-practitioner with seventeen years of experience as school principal, his research interests include instructional leadership, system thinking in school leadership, and education reform. He can be reached at haim.shaked@hemdat.ac.il.

Chen Schechter, $\mathrm{PhD}$, is a professor at the School of Education in Bar-Ilan University, Ramat-Gan, Israel. His research areas include organizational learning, learning from success, educational change, educational leadership, system thinking, and qualitative research methods. 